\title{
The marginal shear stress of Ice Stream B, West Antarctica
}

\author{
Miriam Jackson, Barclay Kamb \\ Division of Geological and Planetary Sciences, California Institute of Technology, Pasadena, California 91125, U.S.A.
}

\begin{abstract}
To ascertain whether the velocity of Ice Stream B, West Antarctica, may be controlled by the stresses in its marginal shear zones (the "Snake" and the "Dragon"), we undertook a determination of the marginal shear stress in the Dragon near Camp Up $\mathrm{B}$ by using ice itself as a stress meter. The observed marginal shear strain rate of $0.14 \mathrm{a}^{-1}$ is used to calculate the marginal shear stress from the flow law of ice determined by creep tests on ice cores from a depth of $300 \mathrm{~m}$ in the Dragon, obtained by using a hot-water icecoring drill. The test-specimen orientation relative to the stress axes in the tests is chosen on the basis of $c$-axis fabrics so that the test applies horizontal shear across vertical planes parallel to the margin. The resulting marginal shear stress is $(2.2 \pm 0.3) \times 10^{5} \mathrm{~Pa}$. This implies that $63-100 \%$ of the ice stream's support against gravitational loading comes from the margins and only $37-0 \%$ from the base, so that the margins play an important role in controlling the ice-stream motion. The marginal shear-stress value is twice that given by the ice-stream model of Echelmeyer and others (1994) and the corresponding strain-rate enhancement factors differ greatly $(E \approx 1-2$ vs $10-12.5)$. This large discrepancy could be explained by recrystallization of the ice during or shortly after coring. Estimates of the expected recrystallization time-scale bracket the $\sim 1 \mathrm{~h}$ time-scale of coring and leave the likelihood of recrystallization uncertain. However, the observed two-maximum fabric type is not what is expected for annealing recrystallization from the sharp single-maximum fabric that would be expected in situ at the high shear strains involved $(\gamma \sim 20)$. Experimental data from Wilson (1982) suggest that, if the core did recrystallize, the prior fabric was a two-maximum fabric not substantially different from the observed one, which implies that the measured flow law and derived marginal shear stress are applicable to the in situ situation. These issues need to be resolved by further work to obtain a more definitive observational assessment of the marginal shear stress.
\end{abstract}

\section{INTRODUGTION}

The stability of the West Antarctic ice sheet is strongly dependent on the stability of the ice streams that are the main outlet of the ice sheet (Bentley, 1987; Alley, 1990). To understand their stability, it is necessary to understand how forces are partitioned within the ice stream. Whereas valley-glacier behavior is controlled both by flow processes at the base and at the margins, in ice streams the width-thickness ratio is so much greater that it was generally considered that ice-stream motion must be controlled mainly by resistive drag at the base, and that the margins were relatively unimportant. However, the shear strength of the till underlying Ice Stream B is too low to support the ice stream (Kamb, 1991). Some authors (e.g. Alley, 1993) have suggested that the ice stream is controlled by "sticky spots" where the till is either stronger than elsewhere or is absent. An alternative suggestion by Echelmeyer and others (1994) and by I. Whillans (personal communication) is that the shear margins play an important role in retarding the flow of the ice stream.

The present paper addresses the above issues by undertaking a determination of the marginal shear stress of Ice Stream B2 at a point in its southern shear margin (the "Dragon"; see Figure 1). From this stress we can estimate how the support of the ice stream against gravitational loading is partitioned between the base and margins, which provides a measure of the relative importance of the base and margins in controlling the flow.
The method of measuring the marginal shear stress is to use the ice itself as a stress meter. The marginal shear strain rate is measured and the shear stress is calculated from the ice-flow law. To determine the flow law, we obtained core samples of ice from the marginal shear zone and subjected them to creep tests in the laboratory.

This work is part of a comprehensive study of ice-stream mechanics by means of borehole geophysics (Engelhardt and others, 1990; Engelhardt and Kamb, 1991, 1994, 1997, in press; Kamb, 1991; Kamb and Engelhardt, 1991), and it bears directly on modelling of ice flow in the marginal shcar zones (Echelmeyer and others, 1994; Raymond, 1996).

\section{FIELD DATA}

The above procedure for shear-stress measurement is carried out for a location (borehole site) "93-6" near the center of the Dragon about $10 \mathrm{~km}$ from Camp Up B, as shown in Figures 1 and 2. At this site, the marginal shear strain rate is at a level that is at or near its maximum in a transverse profile through the site (see Fig. 2). The shear strain rate has been measured by two different methods. One method used repeat aerial photogrammetry and tracked crevasses over a lyear interval to give the velocities of the crevasses and hence the strain rates (Jackson, 1991; Whillans and others, 1993). The marginal strain rate near Up B was found to be approximately $0.14 \mathrm{a}^{-1}$, expressed as engineering shear strain rate $\dot{\gamma}=\partial u_{x} / \partial y$, where $u_{x}$ is the absolute flow 

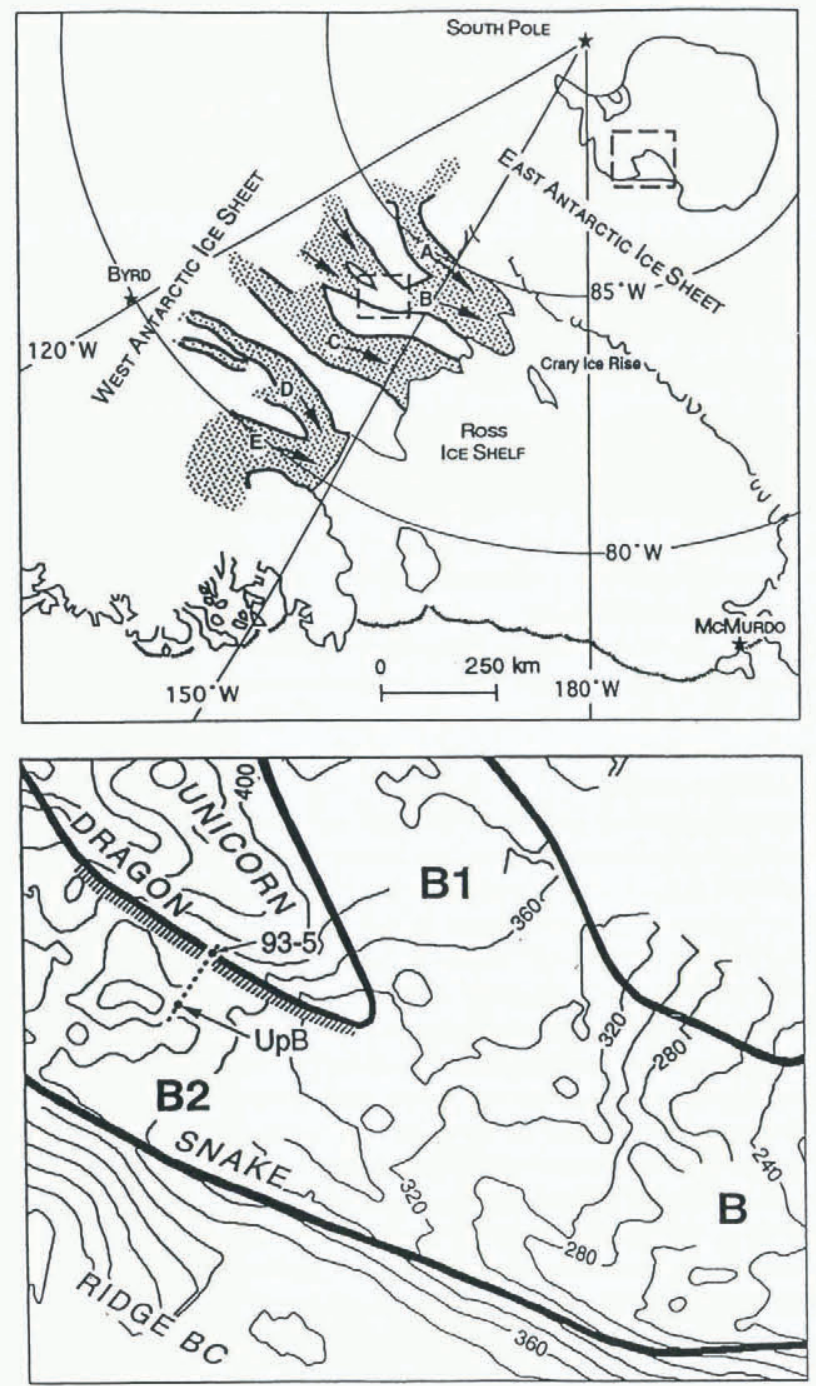

Fig. 1. Location map of boreholes 93-5 and 93-6 (3 m apart) on a profile (dotted) across the south half of Ice Stream B2, passing through camp Up B. The lower panel, based on Retzlaff and others (1993, fig. 7), shows at an enlarged scale the area in the dashed rectangle near the center of the upper panel. Marginal shear zones are shown schematically with heavy lines; the Dragon is shown with added cross-hatching to approximate its actual width. Surface-contour elevations are in meters.

velocity in the $x$ (downstream) direction and $y$ is the transverse coordinate (perpendicular to $x$ ). In the second method, Echelmeyer and others (1994) made repeated ground surveys of a profile of marker poles placed across the shear margin, through site 93-6, obtaining the velocity profile reproduced in Figure 2. According to Echelmeyer and others (1994; Fig. 2b) the shear strain rate at site 93-6 is $0.15 \mathrm{a}^{-1}$. In our evaluation of the marginal shear stress we take $\dot{\gamma}=0.14 \mathrm{a}^{-1}$.

\section{ICE SAMPLES}

The ice tested to determine the flow law was obtained in late December 1993 from a depth of $300 \mathrm{~m}$ in borehole 93-6, by means of a hot-water ice-core drill used in conjunction with standard hot-water drilling from the surface down to $300 \mathrm{~m}$. The core drill retrieves azimuthally unoriented ice cores of maximum diameter $7.0 \mathrm{~cm}$ and maximum length $2 \mathrm{~m}$. Two cores, each of length $2 \mathrm{~m}$, were obtained from depths 300

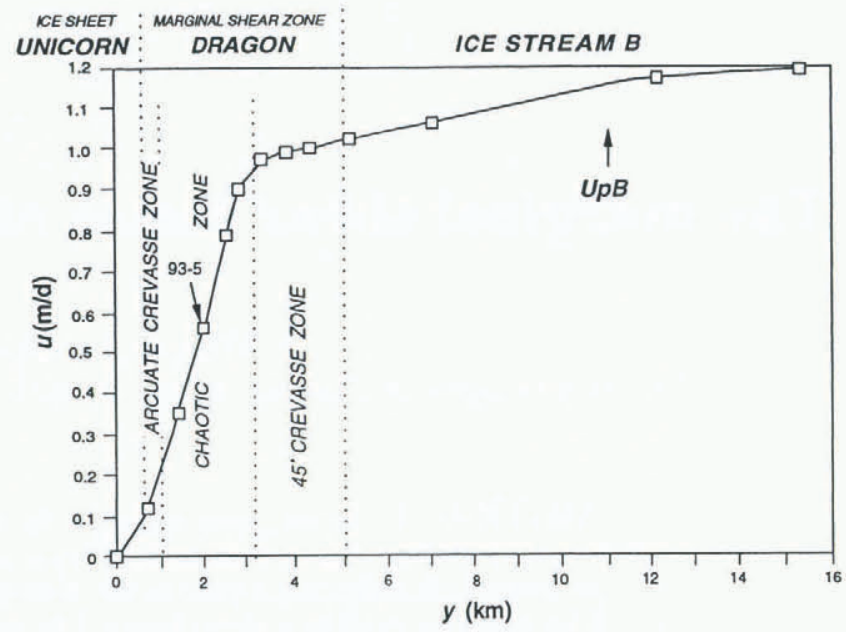

Fig. 2. Ice-stream flow velocity $u$ along the dotted profile in Figure 1, showing the relation between the velocity profile and the marginal shear zone of Ice Stream B2 (the Dragon). On the left (south) is the interstream ridge called the "Unicorn"

(Fig. 1). The locations of $U p B$ and borehole 93-5 on the profile are marked; borehole 93-6 is $3 \mathrm{~m}$ away from 93-5. The lightly dotted lines show subdivision of the shear zone into three sub-zones. The flow velocities are preliminary values kindly supplied by K. Echelmeyer (personal communication). The (transverse) y coordinate is measured from 0 at the south end of the profile.

$304 \mathrm{~m}$ in borehole 93-6, where the total ice thickness is approximately $950 \mathrm{~m}$. The $300 \mathrm{~m}$ depth of the cores was chosen as a depth great enough to have ice of suitable texture and be below the disturbing effects of crevasses and yet shallow enough that the marginal shear strain rate measured at the surface is expected to be applicable. It is also a depth tolerable for drilling under the restrictive conditions in the Dragon. Access to site 93-6 for people and equipment (manhauled) required special precautions and involved special difficulties because of the very extensive crevassing.

After retrieval, the ice cores were kept as cold as possible (c. $-10^{\circ} \mathrm{C}$ ) for $2 \mathrm{~d}$ in insulated Tilson boxes buried in the snow and shielded from solar radiation with plywood sheets. The boxes were then taken by air (cold deck LC-130 flight) to McMurdo Station, where they were stored at $-22 \mathrm{C}$ for about 1.5 months, and where preliminary studies of the ice were made. The boxes were then shipped by sea to the United States in a refrigerated shipping container at $-20^{\circ} \mathrm{C}$, and delivered to Pasadena from Port Hueneme (transport time $1.5 \mathrm{~h}$ ) where they were put into cold-room and deep-freeze storage at $-23^{\circ} \mathrm{C}$. The total elapsed time from retrieval to testing of the samples used in this study was $1.5-2.5$ years, most of it at a temperature of $-23^{\circ} \mathrm{C}$. This temperature history makes it unlikely that the ice underwent recrystallization before being tested (Gow, 1994), except possibly during the hot-water core-drilling operation as discussed in section 7 .

In the present study, ice from one of the two cores from borehole 93-6, core No. 93-6-1, was used in the creep tests. Using only a single core made it possible to keep track of the relative orientations of all thin sections and test specimens.

From the ice core, 11 oriented thin sections (c. $0.5 \mathrm{~mm}$ thick) were made with a microtome from slabs of ice cut from the core with a band saw and cemented to glass plates with cyanoacrylate glue. An example of the grain texture shown in the sections is given in Figure 3. The mean grain 


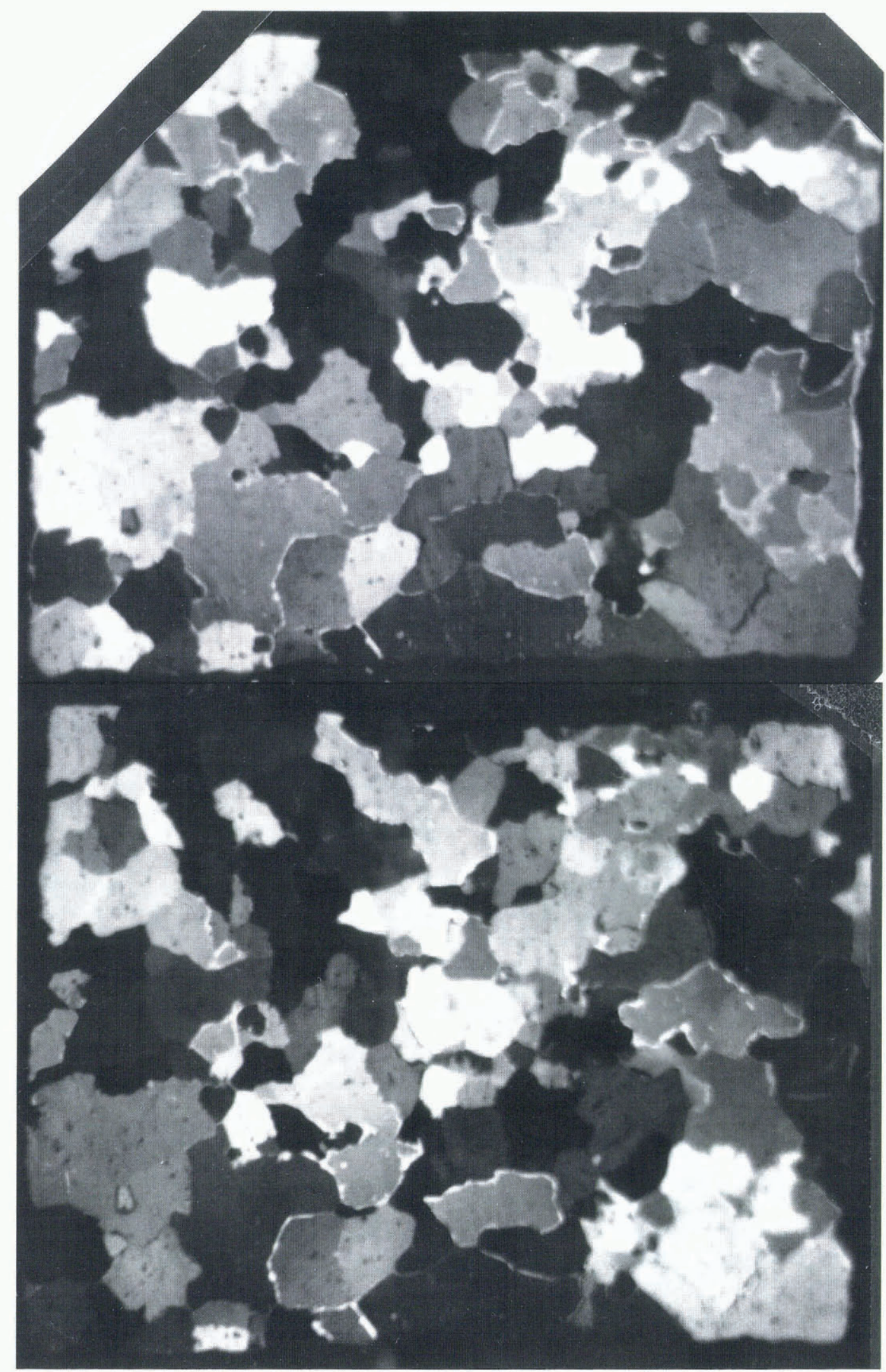

Fig. 3. Thin section of ice from specimen. No. 2 viewed between crossed polarizers. The section is cut parallel to the (vertical) core axis, which runs left and right across the photograph. For scale, the ice measures $5.9 \mathrm{~cm}$ in that direction. In order to make all of the grains visible, the photograph shows the section twice: in the upper half, and then repeated in the lower half with the direction of polarization rotated $45^{\circ}$ with respect to the first.

area, as measured by counting all the grains within a given area of a vertical thin section, is $15 \mathrm{~mm}^{2}$, but some grains are up to $70 \mathrm{~mm}^{2}$ in area. The grain shapes are irregular (nontessellate) and interlocking, with suturing of grain boundaries, as is normal for ice that has recrystallized during deformation. The grain-size and shape are comparable to that for presumably shear-deformed ice from depth $\sim 1500 \mathrm{~m}$ in the Byrd core (Gow and Williamson, 1976, figs 2 and 3) and from depth $\sim 1100 \mathrm{~m}$ in the Camp Century core (Herron and Langway, 1982). Some grains contain planar basal cleavage cracks, seen in thin section and also when the core was first brought to the surface; they doubtless formed on release of pressure, either during the core sampling or during thin sectioning. 

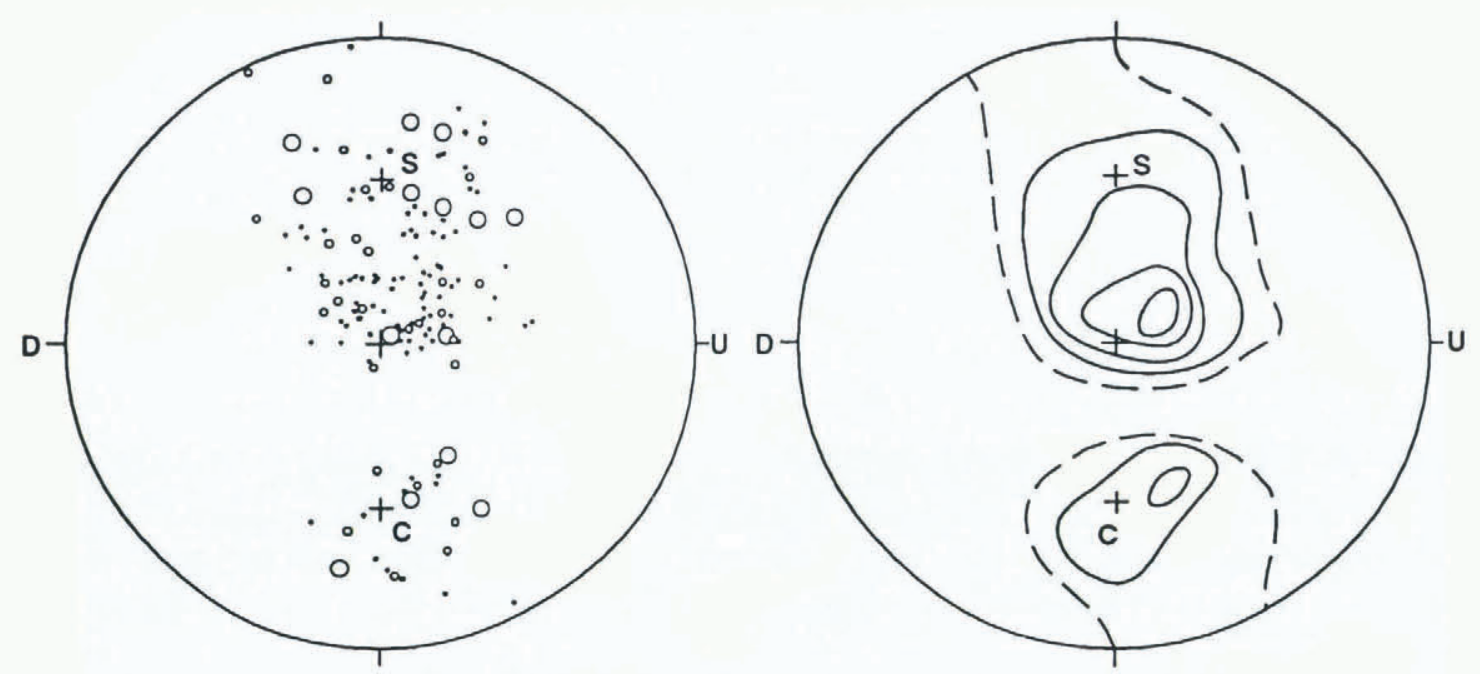

Fig. 4. c-axis fabric of ice from the thin section shown in Figure 3. Equal-area plot, on the lower hemisphere. 139 c-axes are plotted. The size of each crystal is indicated by the plotting symbol as follows: a large open circle indicates a grain whose longest dimension is $\geq 1 \mathrm{~cm}$; small open circle, longest dimension in the range $0.5-1 \mathrm{~cm} ;$ dot, longest diameter $<0.5 \mathrm{~cm}$. For the contoured diagram, the points were counted with a counting area of $2.4 \%$ of the area of the hemisphere. $(2.4 \%$ was used rather than the more usual $1 \%$ to give a better representation of the fabric, following the methods of Kamb (1959) ). Solid contours are at 1, 2, 3,4\% per $1 \%$ of area, dashed contour at $0.3 \%$ per $1 \%$. The core axis runs from $U(u p)$ to $\mathrm{D}$ (down). The axis of compression in the creep test is the unlabelled tick at the top of the equatorial circle (or at the bottom). The pole of the shear plane (or plane of maximum resolved shear stress) is at $S, 45^{\circ}$ from the compression axis, and its conjugate plane is at $C$.

$c$-axis fabrics were measured for seven of the above thin sections, some in horizontal and some in vertical orientations. Although there is statistical fluctuation in the fabric diagrams from section to section, the general pattern is consistent: two fairly broad, unequally strong maxima, both centered approximately in the horizontal plane and at an angle of about $50^{\circ} \pm 10^{\circ}$ between them. An example is shown in Figure 4. This is the general type of pattern expected for simple shear in a horizontal direction across vertical planes (Kamb, 1972, p. 236), which is the strain geometry expected in the shear margin. A complete treatment of fabric data from within and outside the shear margin will be given in a later paper.

\section{CREEP TESTS}

The ice core to be tested was cut with a band saw into rectangular parallelepipeds in the required orientation (see below) and the faces of the parallelepipeds were smoothed with a file. The pieces were tested in unconfined uniaxial compression between plane-parallel stainless-steel platens (Fig. 5). Test pieces were of average height $4.1 \mathrm{~cm}$ parallel to the compressional axis and average cross-sectional area $22 \mathrm{~cm}^{2}$ in the plane perpendicular to that axis. The test pieces were cut from the core in an orientation such that the core axis was perpendicular to the compression axis, and the stronger of the two $c$-axis fabric maxima was at $45^{\circ}$ to the compression axis, i.e. centered at point $\mathrm{S}$ in Figure 4. Because of statistical fluctuations in fabric from one thin section to another cut in the same orientation with respect to the core, in some sections the maximum is found to deviate somewhat from the intended position at $\mathrm{S}$, which was established from another thin section. This is the case in Figure 4. This makes the compression test apply maximum shear stress to the test specimen in the same orientation as marginal shear stress was applied to it in the ice sheet, namely, in a horizonal direction across vertical planes parallel to the margin. This relation holds because the stronger $c$-axis maximum is normal to the plane of simple shear (Kamb, 1972, p. 236).

Although a measurement of shear stress is the objective, the creep test used is a compression test because of the wellknown difficulties associated with direct shear-type tests. The compression test is a permissible substitute because of the insensitivity of the flow law to the mean stress, because of the equivalence of simple shear and pure shear for the

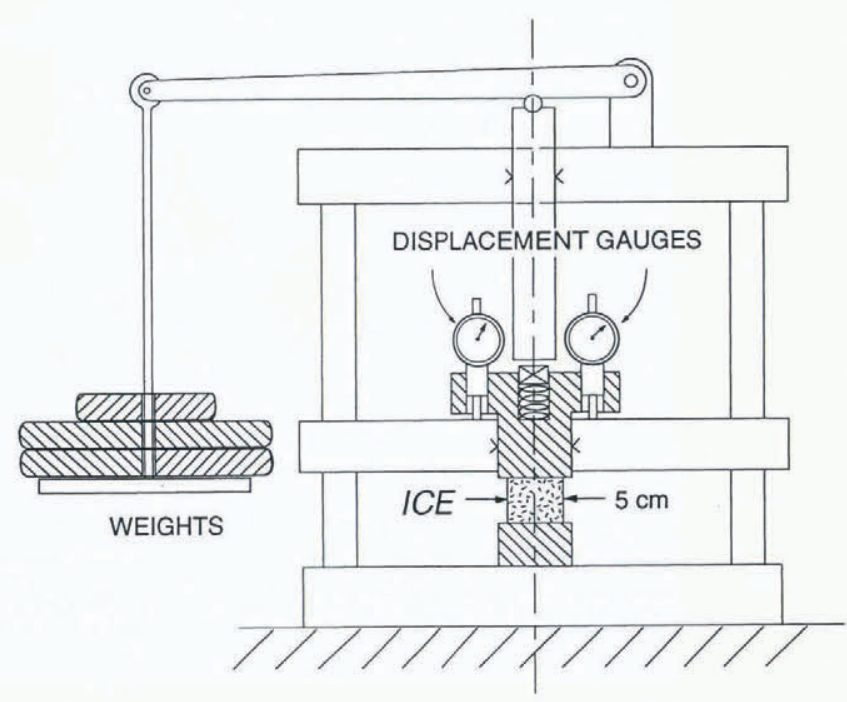

Fig. 5. Schematic diagram of test apparatus. The test specimen, approximately a cube of size $5 \mathrm{~cm}$, is compressed between the upper and lower platens, shown cross-hatched. The upper platen is loaded by the weights via the lever and upper loading shaft, which presses on a load cell (identified by the symbol " $\times$ " in the diagram) and in turn on a load-transfer spring to protect the ice from loading shocks. The displacement gauges (Mitutoyo 543) measure the motion of the upper platen relative to the loading frame. The frame dimension is $0.4 \mathrm{~m}$. Surfaces marked with a " $v$ " are close-sliding fits for mechanical stability in loading. 
Table 1. Specimen dimensions and test data, (1) at lower stress level and (h) at higher stress level

\begin{tabular}{|c|c|c|c|c|c|c|c|c|c|c|c|}
\hline \multirow[t]{4}{*}{$\begin{array}{l}\text { Specimen } \\
\text { number }\end{array}$} & \multirow{4}{*}{$\begin{array}{l}\text { Height } \\
\qquad \begin{array}{l}L_{z} \\
\mathrm{~cm}\end{array}\end{array}$} & \multirow{4}{*}{$\begin{array}{l}\text { Area } \\
L_{x} L_{y} \\
\mathrm{~cm}^{2}\end{array}$} & \multirow{2}{*}{\multicolumn{2}{|c|}{ Test duration }} & \multirow{3}{*}{\multicolumn{2}{|c|}{$\begin{array}{c}\text { Applied stress } \\
\text { (compression) } \\
\sigma \\
\sigma \\
10^{5} \mathrm{~Pa}\end{array}$}} & \multirow{3}{*}{\multicolumn{2}{|c|}{$\begin{array}{l}\text { Compressive } \\
\text { strain rate } \\
\dot{e} \\
\mathrm{a}^{-1} \quad \mathrm{a}^{-1}\end{array}$}} & \multicolumn{3}{|c|}{$\begin{array}{l}\text { Overall decrease in } \\
\text { specimen dimensions }\end{array}$} \\
\hline & & & & & & & & & \multirow{3}{*}{$\begin{array}{c}-\Delta L_{x} \\
\%\end{array}$} & \multirow{3}{*}{$\begin{array}{c}-\Delta L_{y} \\
\%\end{array}$} & \multirow{3}{*}{$\begin{array}{c}-\Delta L \\
\%\end{array}$} \\
\hline & & & \multicolumn{2}{|c|}{ d } & & & & & & & \\
\hline & & & (1) & (h) & (1) & (h) & (1) & (h) & & & \\
\hline 1 & 3.9 & 22 & 8 & 9 & 4.94 & 5.45 & 0.073 & 0.097 & 3.3 & 1.1 & 1.7 \\
\hline 2 & 3.7 & 21 & 8 & 8 & 4.42 & 5.14 & 0.056 & 0.091 & 3.2 & 1.3 & 2.6 \\
\hline 3 & 4.5 & 23 & 9 & 9 & 4.26 & 4.60 & 0.053 & 0.066 & & - & - \\
\hline 4 & 4.4 & 22 & 10 & 14 & 4.75 & 5.31 & 0.068 & 0.093 & 12.8 & 1.3 & 3.5 \\
\hline
\end{tabular}

small strains involved in the tests, and because of the expected effect of flow anisotropy due to the $c$-axis fabric (discussed in section 5). The testing apparatus is shown schematically in Figure 5. Compressive stress is applied to the upper platen by weights acting through a lever of mechanical advantage 11.5. The applied load is measured with a load cell and the displacement of the upper, moveable platen is measured with two Mitutoyo 543 digital displacement indicators, which can resolve displacements of $0.001 \mathrm{~mm}$. The gauges are located symmetrically on opposite sides of the load axis in order to measure the movement of the loading platen on the center line by averaging the readings of the two indicators and thus eliminating the effect of any slight tilting that occurs. The shortening displacement, load and temperature near the specimen are recorded on a data $\log$ ger as a function of time. The apparatus is enclosed in a thermally insulated compartment to damp the roomtemperature fluctuations caused mainly by the cyclic operation of the refrigeration defrost system. The rms variation in temperature in the air near the test specimens was $0.1^{\circ} \mathrm{C}$.

In carrying out creep tests to define the marginal shear stress, each specimen was tested at two stress levels, such that the resulting two shear strain rates bracketed (or nearly bracketed) the observed marginal shear strain rate of $0.14 \mathrm{a}^{-1}$. The marginal shear stress is then obtained by nonlinear interpolation between (or slight extrapolation from) the two data points, as explained in the section 5a. The shear stress across the shear plane is one-half of the compressive stress acting at $45^{\circ}$ to this plane in the test, and for pure shear the compressive shear strain rate sought in the test is one-half the observed marginal shear strain rate of $0.14 \mathrm{a}^{-1}$, hence the compressional stress levels in the tests were chosen to give measured longitudinal strain rates $\dot{e}$ bracketing the value $\dot{e}=0.07 \mathrm{a}^{-1}$. (These relations follow from Mohr's circle.)

Four ice specimens from core No. 93-6-1 were tested in the above way. The temperature for all tests was $-22.0 \pm 0.1^{\circ} \mathrm{C}$, fairly close to the observed temperature of $-24.1^{\circ} \mathrm{C}$ at depth $300 \mathrm{~m}$ in borehole No. 93-5, adjacent to No. 93-6 (Harrison and Echelmeyer, 1994). Test parameters and results are listed in Table 1 . Test 1 refers to the creep test at the lower stress, test $\mathrm{h}$ to that at the higher stress. Typical test data are given in Figure 6, which shows platen displacement, load and temperature vs time for the tests on specimen No. 1. Each test at a given stress was allowed to run uninterrupted for 8 to as long as $14 \mathrm{~d}$ (individual figures in Table 1), until the strain rate became stationary once the large initial transient creep rate had died away. The criterion for steady strain rate was that the average strain rate over the last day of the test be no more than $0.003 \mathrm{a}^{-1}$ smaller than the average over the last
$3 \mathrm{~d}$. The strain-rate value given for each test in Table 1 is the last $3 \mathrm{~d}$ average value.

As illustrated in Figure 6, the testing of each specimen began with the preliminary application of a load considerably below the test 1 load, for a period of several to $10 \mathrm{~d}$. The strain rates at these low loads did not reach a steady state as reliably as at the higher stresses of test $\mathrm{l}$ and test h, hence the results of the low-load tests are not used in determination of the marginal shear stress. However, the time spent in the preliminary low-load part of each run was of value, we think, in counting towards the accumulation of primary creep strain needed to reach steady state in tests $\mathrm{l}$ and $\mathrm{h}$.

In interpreting the results in Table 1 in terms of the mar-
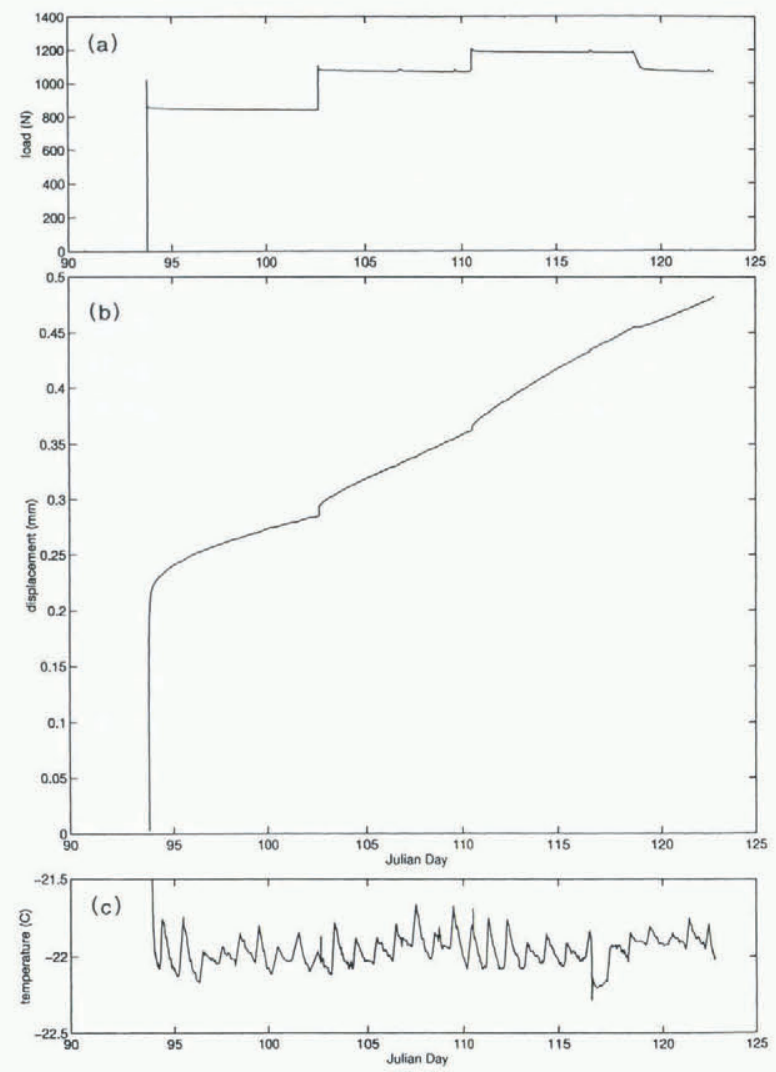

Fig. 6. Test data for specimen No. 1. (a) shows the applied load and (b) the response in terms of displacement of the upper platen vs time. (c) records the air temperature alongside the specimen. Test l runs from J.D. 102 to 110, and test $h$ from J.D. 110 to 119, after which a run at a stress level near that of test $l$ is done as a check. The run from F.D. 94 to 102 is an example of the type of low-load preliminary test mentioned in the text. 
ginal shear stress, as done in section 5 , we assume that the core-sampling procedure captured the ice in its in-situ structural state, in tertiary creep at very large shear strain. Thus, in the laboratory creep tests the stationary stain rate that was reached once the transient creep had died away is the rate for renewed tertiary creep, as has been observed for stopped and restarted laboratory tests (Budd and Jacka, 1989, p. 116, 126, fig. 8, curves L3). It is thus the strain rate appropriate to the in-situ flow of the ice prior to core sampling. In section 7 the possibility that the above assumption is violated due to annealing recrystallization is considered.

\section{INTERPRETATION}

\section{a. Marginal shear stress}

The strain-rate vs stress data in Table 1 can be interpreted in a straightforward way by assuming that a Glen-type flow law applies to the ice in shear across vertical planes parallel to the margin:

$$
\dot{\gamma}=C \tau^{n}
$$

where $\dot{\gamma}$ is engineering shear strain rate across the marginal planes, $\tau$ is the shear stress across these planes and $C$ is a flow-law constant similar to the $A$ that is usually used. The marginal shear stress $\tau_{\mathrm{M}}$ is the value of $\tau$ that produces the observed marginal shear strain rate of $\dot{\gamma}_{\mathrm{M}}=0.14 \mathrm{a}^{-1}$ :

$$
\tau_{\mathrm{M}}=\left(\dot{\gamma}_{\mathrm{M}} / C\right)^{\frac{1}{n}}
$$

The straightforward way to obtain $C$ from the creep tests is to assume that the $c$-axis fabric is accompanied by a flow anisotropy such that the axial compression $\sigma$ in the tests, applied at $45^{\circ}$ to the marginal shear planes, produces a simple shear strain rate $\dot{\gamma}$ across these planes. In this case, from Mohr's circle $\tau=\sigma / 2$ and $\dot{e}=\dot{\gamma} / 2$ where $\dot{e}$ is the axial shortening strain rate produced by $\sigma$. Hence, from Equation (1)

$$
\dot{e}=B \sigma^{n}
$$

where

$$
B=C / 2^{n+1} .
$$

The reason for introducing $B$ as a separate flow parameter will become apparent in section 5b. If we now use Equation (3) to interpret the data for tests 1 and $h$,

\begin{tabular}{|c|c|c|c|c|}
\hline \multirow{4}{*}{$\begin{array}{c}\text { Specimen } \\
\text { number }\end{array}$} & \multirow{4}{*}{$\begin{array}{c}\text { Marginal } \\
\text { shear stress } \\
\tau_{\mathrm{M}} \\
10^{5} \mathrm{~Pa}\end{array}$} & \multirow{4}{*}{$\begin{array}{c}\text { Flow-law } \\
\text { exponent } \\
n\end{array}$} & \multicolumn{2}{|c|}{ Enhancement factor E } \\
\hline & & & Pat. & B. $\&$ J \\
\hline & & & $E_{\mathrm{P}}$ & \\
\hline & & & & \\
\hline 1 & 2.43 & 2.8 & 1.12 & 2.31 \\
\hline 2 & 2.37 & 3.2 & 1.19 & 2.48 \\
\hline 3 & 2.35 & 2.9 & 1.22 & 2.55 \\
\hline 4 & 2.40 & 2.7 & 1.14 & 2.39 \\
\hline
\end{tabular}

$$
\dot{e}_{l}=B \sigma_{1}{ }^{n}, \quad \dot{e}_{\mathrm{h}}=B \sigma_{\mathrm{h}}{ }^{n},
$$

Table 2. Derived results (anisotropic evaluation)

Pat.: $E$ is referred to the flow law of Paterson (1994. p. 97).

B. $\&$ f: $E$ is referred to the flow law of Jacka and Budd (1989, fig. 1). we can obtain $B$ and $n$ by solving Equations (5):

$$
\begin{aligned}
n & =\frac{\log \dot{e}_{\mathrm{h}}-\log \dot{e}_{\mathrm{l}}}{\log \sigma_{\mathrm{h}}-\log \sigma_{\mathrm{l}}} \\
\log B & =\frac{\log \sigma_{\mathrm{l}} \log \dot{e}_{\mathrm{h}}-\log \sigma_{\mathrm{h}} \log \dot{e}_{\mathrm{l}}}{\log \sigma_{\mathrm{l}}-\log \sigma_{\mathrm{h}}} .
\end{aligned}
$$

Then $C$ is obtained from Equation (4) and the marginal shear stress from Equation (2). The above method uses the Glen-type relation in Equation (3) as a means of interpolating (or slightly extrapolating) non-linearly between the data of test 1 and test $\mathrm{h}$ (Table 1) to find the stress $\tau_{\mathrm{M}}$ that corresponds to the observed $\dot{\gamma}_{\mathrm{M}}$.

The results are listed in Table 2 . They indicate a marginal shear stress of $(2.4 \pm 0.2) \times 10^{5} \mathrm{~Pa}$. There is only a modest scatter in the results from the four specimens. The indicated value $n=2.9 \pm 0.3$ is as expected for a shear zone dominated by simple shear (Alley, 1992).

\section{b. Effects of isotropy/anisotropy on the evaluation of $\tau_{\mathrm{M}}$}

The above derivation of $\tau_{\mathrm{M}}$ from the test data implicitly treats the flow of the ice as "perfectly anisotropic" in the way it would be if the fabric were so strong that the ice flowed like a single crystal with its (0001) planes aligned parallel to (or perpendicular to) the marginal planes (see Fig. 7), and with the flow law in Equation (1) relating shear stress $\tau$ and shear strain rate $\dot{\gamma}$ across (0001). There is indeed a welldeveloped fabric with roughly these features, as discussed in section 3. (In Figure 7, the (0001) planes for crystals of the second, weaker maximum in Figure 4 are omitted for clarity; these crystals would contribute to the flow in the same way as the crystals of the first maximum do, if the second maximum were perpendicular to the first.)

There is some qualitative experimental evidence for the assumed flow anisotropy: the extensional strain rate perpendicular to the compression axis (center line in Figure 5) is smaller in the direction parallel to the marginal planes $(x$ axis in Figure 7) than in the direction at $45^{\circ}$ to the marginal plane ( $y$ axis in Figure 7). This relationship is indicated in Figure 7 by the heavy arrows, which represent the extensional/compressional strain rates in the three perpendicular directions $(x, y, z)$ parallel and perpendicular to the compression axis of the tests. The extensional strain rates $\dot{e}_{x}$ and $\dot{e}_{y}$ (Fig. 7) cannot be measured quantitatively in our test specimens because the $x$ and $y$ faces are free faces that become slightly ablated by sublimation during the test, but the final specimen dimensions are always reduced relative to the initial dimensions by a larger amount in the $x$ direction than in the $y$ direction, indicating the $\dot{e}_{x}<\dot{e}_{y}$. The magnitude of the inequality $\dot{e}_{x}<\dot{e}_{y}$ is of the same order as the magnitude of $\dot{e}_{z}$, to judge from figures in the last three columns of Table 1, which give the overall changes in dimensions of each specimen tested (except No. 3, for which the measurements were inadvertently omitted).

Because $\dot{e}_{x}$ and $\dot{e}_{y}$ cannot be measured quantitatively, we cannot make an evaluation of the test data on the basis of a model of parametrically adjustable flow anisotropy (Johnson, 1977; Lliboutry, 1993, p. 412; Paterson, 1994, p. 99), which would include the foregoing treatment of "perfect anisotropy" as a limiting case. We can, however, assess the possible effect of "imperfect anisotropy" on the evaluation by treating the limiting case of complete isotropy of the flow law, the other extreme in the anisotropy/isotropy spectrum. This 


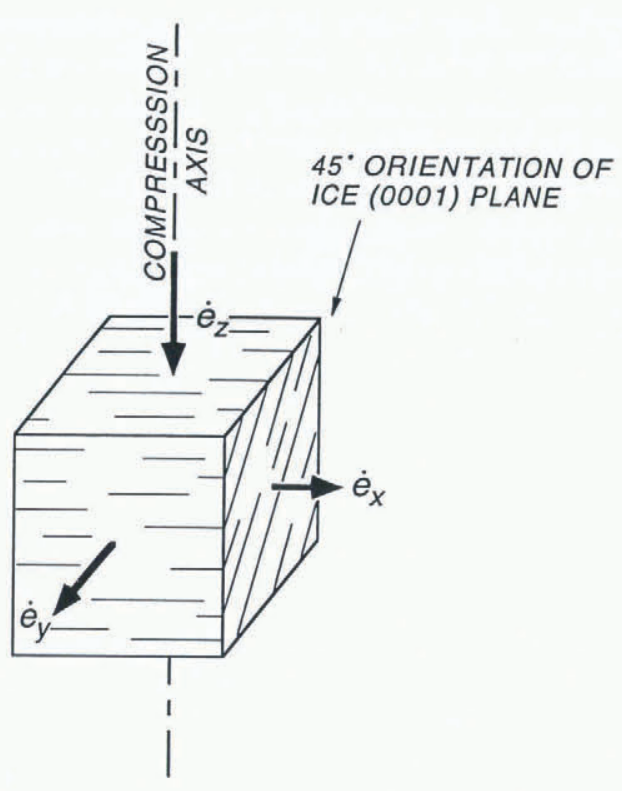

Fig. 7. Schematic illustration of a typical test block, with ice (0001) planes of the main maximum of the c-axis fabric dipping $45^{\circ}$ relative to the top $(z)$ face of the block, which is perpendicular to the compression axis. The planes of the secondary maximum, not shown, would have the same strike and would dip $\sim 20^{\circ}$ in the opposite direction. The strike direction is the core axis, parallel to the $x$ axis. The heavy arrows depict schematically the shortening strain rate parallel to the $z$ axis and the extensional strain rates parallel to the $x$ and $y$ directions, with $\dot{e}_{x}<\dot{e}_{y}$. (The y axis of Figure 2 is different; if shown here it would be perpendicular to the (0001) planes.)

is done in the standard way (Paterson, 1994, p. 92): the flow law is given in the form

$$
\begin{aligned}
\dot{e}_{i j} & =A \tilde{\tau}^{n-1} \tau_{i j}^{\prime} \\
\tilde{\tau}^{2} & =\frac{1}{2} \tau_{i j}^{\prime} \tau_{i j}^{\prime}
\end{aligned}
$$

where $\tilde{\tau}^{2}$ is the second invariant of the stress deviator tensor $\tau_{i j}^{\prime}$ (with tensor summation convention). $A$ is the standard flow parameter. When Equations (8) and (9) are evaluated for unconfined uniaxial compression in the $z$ direction, with $\sigma=-\tau_{z z}$, all other $\tau_{i j}=0$, and $\dot{e}_{z z}=-\dot{e}$, we obtain

$$
\dot{e}=B \sigma^{n}
$$

with

$$
B=2 A / 3^{n+1 / 2} .
$$

Equation (10) has the same form as Equation (3), so the evaluation of $B$ from the test data is the same whether we assume anisotropy or isotropy. The difference is that the isotropic flow parameter $A$ in Equation (8) is calculated from $B$ by Equation (11), whereas the anisotropic flow parameter $C$ in Equation (1) is calculated from $B$ by Equation (4). The marginal shear stress $\tau_{\mathrm{MI}}$ for the isotropic evaluation is calculated from Equations (8) and (9) under the assumption that the flow in the marginal shear zone is pure shear with $\dot{e}_{x x}=0$ ( $x$ axis vertical), $\dot{e}_{y y}=\dot{\gamma}_{\mathrm{M}} / 2$ and $\tau_{y y}^{\prime}=\tau_{\mathrm{MI}}$ (from Mohr's circle), and $\tilde{\tau}=\tau_{y y}^{\prime}$, giving

$$
\dot{\gamma}_{\mathrm{M}}=2 A \tau_{\mathrm{MI}}^{n} \text {. }
$$

If we take $A$ from Equation (12) and substitute into Equation (11), then take $B$ from Equation (11) and substitute into
Equation (4), and finally take $C$ from Equation(4) and substitute into Equation (2), we obtain

$$
\tau_{\mathrm{MA}}=\left(\frac{\sqrt{3}}{2}\right)^{n+1 / n} \tau_{\mathrm{MI}} .
$$

In Equation (13), $\tau_{\mathrm{MA}}$ on the left, which is the same as $\tau_{\mathrm{M}}$ on the left in Equation (2), has been redesignated $\tau_{\mathrm{MA}}$ to call attention to the fact that it is based on the anisotropic treatment in section 5a. From Equation (13), we see that for $n=3, \tau_{\mathrm{MA}}=0.83 \tau_{\mathrm{MI}}$, or $\tau_{\mathrm{MI}}=1.21 \tau_{\mathrm{MA}}$. Thus, the maximum correction to the anisotropic evaluation on account of "imperfect" anisotropy is a $21 \%$ increase in the marginal shear stress over the values listed in Table 2 . The corrected value could be increased in this way at most to $(2.9 \pm 0.2) \times 10^{5}$ Pa. However, the flow indication of anisotropy $\left(\dot{e}_{x}<\dot{e}_{y}\right)$, noted above, suggests that the value is not increased this much.

\section{c. Flow-enhancement factor}

Benchmarks for comparison with the foregoing results are the marginal shear-stress values $\tau_{\mathrm{MP}}$ and $\tau_{\mathrm{MJ}}$ that would be implied if the ice in the marginal zone deformed in accordance with standard minimum strain-rate isotropic flow relations such as the one of Paterson (1994, p. 91) or the one of Jacka and Budd (1989, fig. 1; also given by Budd and Jacka, 1989, fig. 6). At $-22^{\circ} \mathrm{C}$, the Paterson relation is Equation (8) with $n=3$ and $A=A_{\mathrm{P}}=1.4 \times 10^{-16} \mathrm{~s}^{-1}(\mathrm{kPa})^{-3}$, and the Jacka and Budd relation (converted from its expression in terms of octahedral shear values) is the same with $A=A_{\mathrm{J}}=0.67 \times 10^{-16} \mathrm{~s}^{-1}(\mathrm{kPa})^{-3}$. The benchmark stresses $\tau_{\mathrm{MP}}$ and $\tau_{\mathrm{MJ}}$ are obtained from

$$
\dot{\gamma}_{\mathrm{M}}=2 A_{\mathrm{P}} \tau_{\mathrm{MP}}^{n}, \quad \dot{\gamma}_{\mathrm{M}}=2 A_{\mathrm{J}} \tau_{\mathrm{MJ}}^{n},
$$

which are based on Equation (12), with $A$ replaced by $A_{\mathrm{P}}$ or $A_{\mathrm{J}}$, and $\tau_{\mathrm{MI}}$ replaced by $\tau_{\mathrm{MP}}$ or $\tau_{\mathrm{MJ}}$. The results are $\tau_{\mathrm{MP}}=2.51 \times 10^{5} \mathrm{~Pa}$ and $\tau_{\mathrm{MJ}}=3.21 \times 10^{5} \mathrm{~Pa}$. These values, especially $\tau_{\mathrm{MP}}$, are only modestly greater than the value $\tau_{\mathrm{MA}}=(2.4 \pm 0.2) \times 10^{5} \mathrm{~Pa}$ obtained in section $5 \mathrm{a}$, which implies that the $c$-axis fabric has only a slight effect in weakening the actual ice relative to the standard, or else that such weakening is counteracted by other effects that strengthen the ice. The discrepancy between the two benchmark values $\tau_{\mathrm{MP}}=2.5 \times 10^{5} \mathrm{~Pa}$ and $\tau_{\mathrm{MJ}}=3.2 \times 10^{5} \mathrm{~Pa}$ indicates that we cannot take these values as an absolute reference against which to assess weakening in the marginal shear zone.

An alternative representation of these results is in terms of a flow-enhancement factor $E$, which is the factor by which the observed marginal shear strain rate is increased over the shear strain rate that is given by a standard minimum strain-rate isotropic flow law at the same shear stress. Making use of the similarity between Equations (1) and (14), we set $C=2 E A$ so that

$$
\dot{\gamma}_{\mathrm{M}}=2 E A \tau_{\mathrm{MA}}{ }^{n} .
$$

From Equations (14) and (15), it follows that

$$
E_{\mathrm{P}}=\left(\tau_{\mathrm{MP}} / \tau_{\mathrm{MA}}\right)^{n}, \quad E_{\mathrm{J}}=\left(\tau_{\mathrm{MJ}} / \tau_{\mathrm{MA}}\right)^{n} .
$$

Values of $E$ from Equations (16) are listed in Table 2.

The Paterson benchmark shear stress $\tau_{\mathrm{MP}}=2.5 \times 10^{5} \mathrm{~Pa}$ is smaller than the marginal shear stress $\tau_{\mathrm{MI}}=(2.9 \pm 0.2) \times$ $10^{5} \mathrm{~Pa}$ based on the isotropic evaluation of our test data. The corresponding enhancement factor $E_{\mathrm{I}}=\left(\tau_{\mathrm{MP}} / \tau_{\mathrm{MI}}\right)^{n}$ is 0.64 . Thus, according to the isotropic evaluation, the flow is suppressed, not enhanced, relative to the benchmark. 
Such suppression could in principle occur, due for example to a $c$-axis fabric unfavorable to flow (e.g. Shoji and Langway, 1988, fig. 5; Paterson, 1994, fig. 5.7), but we think it more likely that the result indicates that the anisotropic evaluation is closer to being valid than the isotropic one is. This problem does not arise for the Budd and Jacka (1989) benchmark stress $\tau_{\mathrm{MJ}}$, which is greater than $\tau_{\mathrm{MI}}$ and corresponds to $E_{\mathrm{I}}=1.8$.

\section{d. Effect of vertical temperature profile}

The value of the marginal shear stress obtained above applies specifically to depth $300 \mathrm{~m}$, where the ice core was obtained and where the temperature is close to the temperature of the laboratory tests. Because the control of the overall ice-stream motion is exercised in terms of the depthaveraged marginal shear stress, and because the flow of ice is sensitive to the temperature, which increases substantially in the lower half of the ice mass, we need to estimate a temperature correction from the $300 \mathrm{~m}$ shear-stress value $\tau_{\mathrm{M}}$ to a depth-averaged value $\bar{\tau}_{\mathrm{M}}$. This is done with the measured temperature profiles in Figure 8 . A profile to depth $500 \mathrm{~m}$ was measured by Harrison and Echelmeyer (1995) in borehole 93-5, adjacent to the corehole 93-6. It is given in Figure 8a. A profile from depth $500 \mathrm{~m}$ to the bottom at $914 \mathrm{~m}$ was
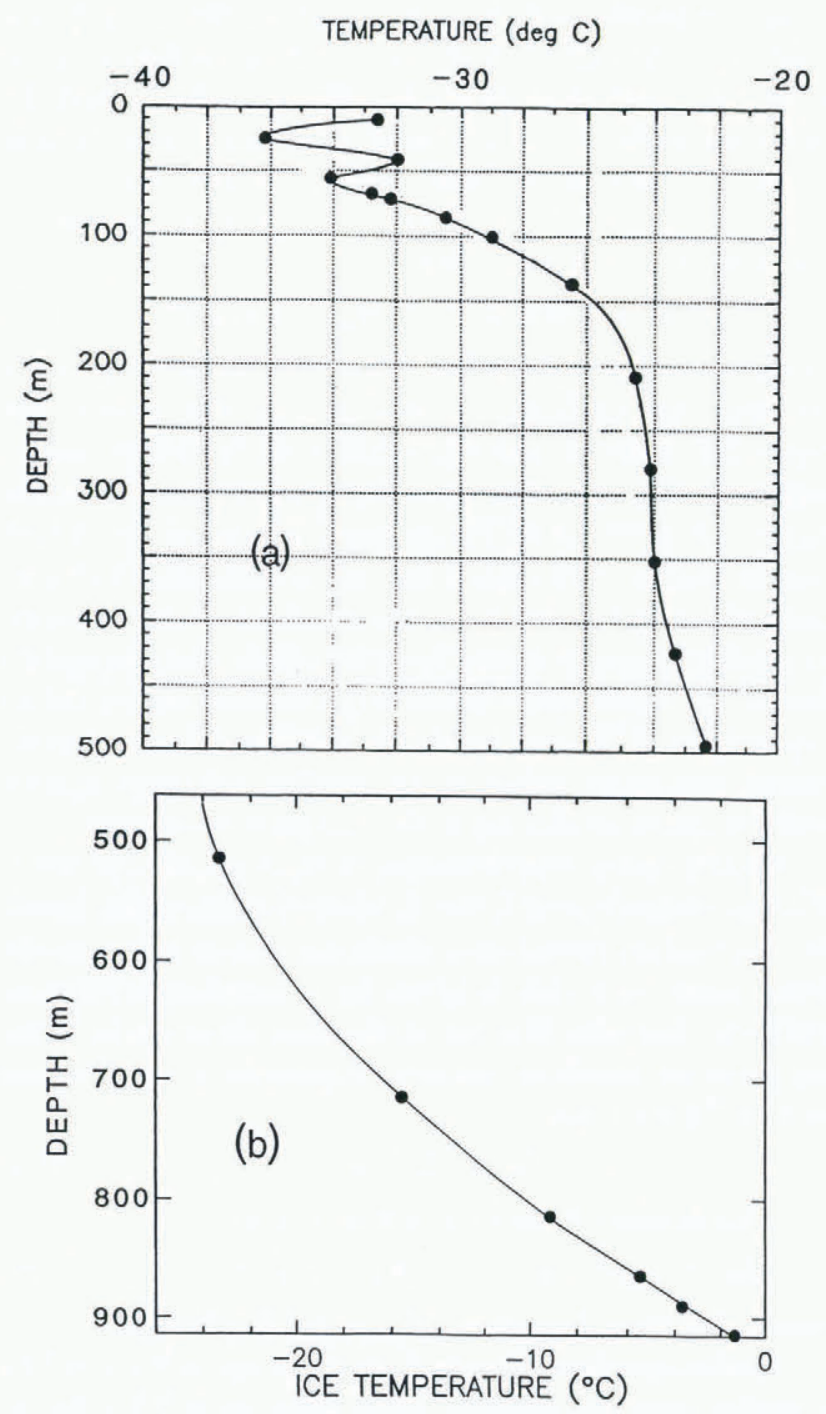

Fig. 8. Temperature profile through the ice sheet near hole 936: (a) in the upper $500 \mathrm{~m}$, from Harrison and Echelmeyer (1995); and (b) in the lower $400 \mathrm{~m}$, in borehole $93-10,1 \mathrm{~km}$ south of 93-6, by H. Engelhardt (personal communication). measured by Engelhardt (personal communication) in borehole 93-10, near the outer edge of the marginal zone $1 \mathrm{~km}$ south of 93-6 at coordinate $y=1.0 \mathrm{~km}$ in Figure 2; it is given in Figure $8 \mathrm{~b}$. These profiles were combined into a single vertical absolute-temperature profile $T(z)$, where $z$ is depth; in this combination, the ice at hole 93-6 was assumed to be $950 \mathrm{~m}$ thick and the temperature curve in Figure $8 \mathrm{~b}$ was accordingly shifted downward by $36 \mathrm{~m}$.

The temperature-dependence of the ice-flow law Equation (1)) is taken in the standard form where $T_{1}$ is $251 \mathrm{~K}$ and $C_{1}$ is the value indicated by the tests, at $T=T_{1} . R$ is the gas constant.

$$
C(z)=C_{1} \exp \left[\frac{Q_{1}}{R}\left(\frac{1}{T_{1}}-\frac{1}{T(z)}\right)\right] .
$$

The activation energy $Q_{1}$ is taken to be $60 \mathrm{~kJ} \mathrm{~mol}^{-1} \mathrm{~K}^{-1}$ for $T$ below $263 \mathrm{~K}=T_{2}$, and $139 \mathrm{~kJ} \mathrm{~mol}^{-1} \mathrm{~K}^{-1}=Q_{2}$ for $T$ above $T_{2}$, where Equation (17) is replaced by

$$
C(z)=C_{1} \exp \left[\frac{Q_{1}}{R}\left(\frac{1}{T_{1}}-\frac{1}{T_{2}}\right)+\frac{Q_{2}}{R}\left(\frac{1}{T_{2}}-\frac{1}{T(z)}\right)\right] .
$$

In calculating the depth-averaged shear stress $\bar{\tau}_{\mathrm{M}}$, we assume that the marginal shear strain rate $\dot{\gamma}_{M}$, which is measured at the surface, is constant with depth. This is probably a good assumption in the upper part of the ice mass but not near the bed. It is an aspect of the problem of strain-rate distribution in the marginal shear zone, which has been considered in detail by Echelmeyer and others (1994) and by Raymond (1996). Because of weakening of the ice near the bed, where the temperature approaches melting, the contribution from that part of the profile to the depth-averaged $\bar{\tau}_{\mathrm{M}}$ is small and the break-down of the constant $\dot{\gamma}_{M}$ assumption is therefore not serious. Thus, the averaging is done by introducing Equations (17) and (18) into Equation (2) and integrating over depth:

$$
\begin{aligned}
\frac{\bar{\tau}_{\mathrm{M}}}{\tau_{\mathrm{M}}}= & \frac{1}{h}\left\{\int_{0}^{z_{2}} \exp \left[\frac{Q_{1}}{n R}\left(\frac{1}{T(z)}-\frac{1}{T_{1}}\right)\right] \mathrm{d} z\right. \\
& +\int_{z_{2}}^{h} \exp \left[\frac{Q_{1}}{n R}\left(\frac{1}{T_{2}}-\frac{1}{T_{1}}\right)\right. \\
& \left.\left.+\frac{Q_{2}}{n R}\left(\frac{1}{T(z)}-\frac{1}{T_{2}}\right)\right] \mathrm{d} z\right\} .
\end{aligned}
$$

$h$ is the ice thickness $(950 \mathrm{~m})$ and $z_{2}$ is the depth at which $T\left(z_{2}\right)=T_{2}$. In obtaining Equation (19) from Equation (2), we replace $\left(\dot{\gamma}_{\mathrm{M}} / C_{1}\right)^{1 / n}$ by $\tau_{\mathrm{M}}$, the marginal shear stress at $300 \mathrm{~m}$ depth, discussed in section 5 a.

When Equation (19) is evaluated numerically with the $T(z)$ data in Figure 8, the temperature-averaging factor $\bar{\tau}_{M} / \tau_{M}$ is found to have the value 0.98 , hardly different from 1 , so that there is no appreciable temperature correction for the depth-averaged marginal shear stress. Evidently, the ice-weakening effect of the warmer temperatures below a depth of about $600 \mathrm{~m}$ (Fig. 8b) is offset by the strengthening due to the low temperatures (to $-36^{\circ} \mathrm{C}$ ) above $300 \mathrm{~m}$ depth (Fig. 8a); also, the actual temperature at $300 \mathrm{~m}$ is $2^{\circ} \mathrm{C}$ lower than the test temperature of $-22^{\circ} \mathrm{C}$.

The anomalous deep-temperature minimum at $\sim 50 \mathrm{~m}$ depth is due, as explained by Harrison and Echelmeyer (1994), to the heat-pump action of thermal convection in the crevasses that pervade the marginal shear zone to a depth $\sim 50 \mathrm{~m}$. Because of this crevassing, the uppermost $50 \mathrm{~m}$ of the ice mass must be weakened relative to the unfractured ice below. Avery crude estimate of this weakening 
is a factor 0.5 , on the basis that the tensile principal stress in the marginal shear zone is relieved by tensile fracture. If we apply this weakening factor to the upper $100 \mathrm{~m}$ of the ice column (choosing the overestimate $100 \mathrm{~m}$ to assess the maximum effect), and correct the calculation in Equation (19) accordingly, we obtain a combined temperature-and-fracture correction factor of 0.91 , and a depth-averaged shear stress $\bar{\tau}_{\mathrm{M}}=2.2 \times 10^{5} \mathrm{~Pa}$ for the anisotropic evaluation and $\bar{\tau}_{\mathrm{MI}}=\bar{\tau}_{\mathrm{MI}}=2.6 \times 10^{5} \mathrm{~Pa}$ for the isotropic evaluation.

\section{FORCE BALANCE IN THE ICE STREAM}

The foregoing evidence and argument lead to a depth-averaged marginal shear stress $\bar{\tau}_{\mathrm{M}}$ of about $(2.2 \pm 0.3) \times 10^{5} \mathrm{~Pa}$. This is surprisingly large in relation to the maximum stresses of about $1 \times 10^{5} \mathrm{~Pa}$ that are normally found (calculated) in glaciers and ice sheets (Paterson, 1994, p. 242). The situation can be rationalized by noting that the marginal shear strain rate $\left(0.14 \mathrm{a}^{-1}\right)$ is comparable to that often observed in temperate glaciers (e.g. Meier and others, 1974, fig. 6) but the ice is much colder and its viscosity is consequently higher.

Another contrast is that in normal glaciers the marginal shear stress $\tau_{\mathrm{M}}$ is almost always smaller than the basal shear stress $\tau_{\mathrm{B}}$, whereas here $\tau_{\mathrm{M}}$ is much greater than $\tau_{\mathrm{B}}$. This is seen in the ice-stream mechanical model of Echelmeyer and others (1994, fig. 5), in which $\tau_{\mathrm{B}}$ is only about $0.06 \times 10^{5}$ $\mathrm{Pa}$. The low $\tau_{\mathrm{B}}$ can be attributed to the weakness of the subglacial till, which has a measured strength $\sim 0.02 \times 10^{5} \mathrm{~Pa}$ (Kamb, 1991, p. 16,587).

The large marginal shear stress must play a major role in controlling the motion of the ice stream. This can be judged by calculating for a simple model the support provided by $\tau_{\mathrm{M}}$ against the downslope component of gravity and comparing it with the support provided by $\tau_{\mathrm{B}}$. In a general way, the larger the fraction of support provided by $\tau_{\mathrm{B}}$ or $\tau_{\mathrm{M}}$, the greater the control exerted by the base or the margin on the flow velocity. The model (Fig. 9) treats an ice stream of longitudinally constant cross-section, assumes no longitudinal gradients of flow and idealizes the cross-section as composed of two quadrilaterals symmetrical across the center line. (The neglect of longitudinal gradients has been discussed by Jackson (1991, p. 77) and by Echelmeyer and others (1994, p. 530).) Based on borehole drilling and on a radar profile by Shabtaie and Bentley $(1988$, fig. 4 b), the centerline ice depth is $h_{\mathrm{C}}=1200 \mathrm{~m}$ and the thickness at the margin is $h_{\mathrm{M}}=900 \mathrm{~m}$. The balance of forces for the cross-section, balancing the downslope component of gravity integrated over the cross-section against the basal drag and the marginal drag over unit length of the ice stream, is

$$
\rho g \frac{1}{2}\left(h_{\mathrm{C}}+h_{\mathrm{M}}\right)(\sin \alpha) W=\bar{\tau}_{\mathrm{B}} W+2 \bar{\tau}_{\mathrm{M}} h_{\mathrm{M}}
$$

where $\alpha$ is the surface slope, $W$ is the ice-stream width (31 $\mathrm{km}), g$ is gravity and $\rho$ is ice density. (The slight effect of the small transverse slope of the bed is neglected.) The factor 2 comes from the two margins (left and right), and $\bar{\tau}_{\mathrm{M}}$ is averaged vertically as in section 5 d. Equation (20) can be usefully expressed in terms of the driving stress $\bar{\tau}_{\mathrm{D}}=\rho g \bar{h} \sin \alpha$ (averaged over the cross-section, with $\left.\bar{h}=\frac{1}{2}\left(h_{\mathrm{C}}+h_{\mathrm{M}}\right)=1050 \mathrm{~m}\right)$ :

$$
\bar{\tau}_{\mathrm{D}}=\bar{\tau}_{\mathrm{B}}+2 h_{\mathrm{M}} \bar{\tau}_{\mathrm{M}} / W \text {. }
$$

The surface slope $\alpha$ of the ice stream is not well defined locally because of complex surface irregularities on a scale of a few kilometers (Jackson, 1991, fig. 3). For illustrative purposes, we first take the average slope over an approximately
$45 \mathrm{~km}$ reach centered on Up B, which is $\alpha=0.0013$ \pm 0.0003 . This is based on a surface-elevation map of Ice Stream B by Retzlaff and others (1993, fig. 7). The same value of $\alpha$ was used in the model of Echelmeyer and others (1994, p. 531). It gives $\bar{\tau}_{\mathrm{D}}=0.12 \times 10^{5} \mathrm{~Pa}$. When this value and $\bar{\tau}_{\mathrm{M}}=2.2 \times 10^{5} \mathrm{~Pa}$ are introduced into Equation $(21)$ and it is solved for $\tau_{\mathrm{B}}$, the result is $\tau_{\mathrm{B}}=0.0 \times 10^{5} \mathrm{~Pa}$. Thus, according to this model, all of the mechanical support for the ice stream comes from the margins and the basal shear stress is negligible. If, instead of $\alpha=0.0013$ we use $\alpha=0.00225$, which is our estimate of the local slope averaged over a longitudinal interval of $\approx 5 \mathrm{~km}$ about the dotted profile in Figure 1 , we obtain $\tau_{\mathrm{B}}=0.08 \times 10^{5} \mathrm{~Pa}$. This is nearly the same as $\tau_{\mathrm{B}}=0.06 \times 10^{5} \mathrm{~Pa}$ in the Echelmeyer and others (1994, fig. 5a) model (except near the margins, where $\tau_{\mathrm{B}}$ decreases). In this case, the fraction of the driving force that is supported by the basal shear stress, $\bar{\tau}_{\mathrm{B}} / \bar{\tau}_{\mathrm{D}}$, is $37 \%$, and the fraction supported by the margins, $2 h_{\mathrm{M}} \bar{\tau}_{\mathrm{M}} / W \bar{\tau}_{\mathrm{D}}$, is $63 \%$. The value of $\alpha$ could possibly be even higher - Alley and others (1987) used 0.0027 - which would further lower the fractional support from the margins. The marginalsupport fractions given by the different models of Echelmeyer and others (1994) range from 35 to $93 \%$.

Although this shows that the margins tend to dominate in controlling the motion of the ice stream in its present active configuration, we should not lose sight of the fact that the fundamental controlling mechanism that allows the ice stream to attain its rapid motion in the first place is the mechanism of basal lubrication, which causes the low basal shear stress.

\section{DISCREPANGIES AND THE POSSIBLE ROLE OF RECRYSTALLIZATION}

The value $\bar{\tau}_{\mathrm{M}}=2.2 \times 10^{5} \mathrm{~Pa}$ is high by a factor of almost 2 relative to the results of a mechanical model of the marginal shear zone by Echelmeyer and others (1994, p. 535), which gives a marginal shear stress of about $1.2 \times 10^{5} \mathrm{~Pa}$. The corresponding enhancement factor $E$ for ice in the high $\dot{\gamma}$ marginal zone is $E=10-12.5$ (Echelmeyer and others,

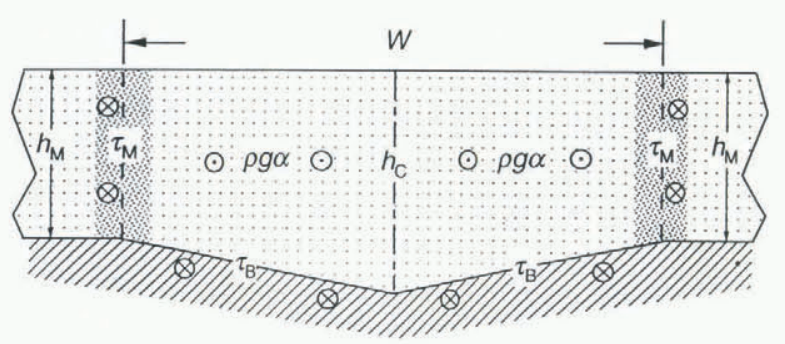

Fig. 9. Idealized cross-section of Ice Stream B at camp Up B, for calculation of the balance of longitudinal forces (not drawn to scale). The ice is dotted and the marginal shear zones are shown heavily dotted. The bed is cross-hatched. The ice is taken to be $1200 \mathrm{~m}$ thick $\left(=h_{\mathrm{C}}\right)$ at the center line and $900 \mathrm{~m}$ thick $\left(=h_{\mathrm{M}}\right)$ at the margins. The width of the ice stream is $W=31 \mathrm{~km}$. The gravitational body force component $\rho g \sin \alpha$ acts on the ice in the downstream direction, perpendicular to the cross-section; this is represented by the "arrow heads"seen end on - circles with dot in the center. The shear stress at the bed and margins (drag stress acting upstream on the ice, resisting the flow) is represented by the "arrow tails" (circles with a cross) just outside the periphery of the crosssection. 
1994, figs 3 b and 4), which is 5-10 times larger than the $E$ values that we obtain (Table 2). These differences in $\tau_{\mathrm{M}}$ and $E$ constitute a fundamental discrepancy, which needs to be clarified. We first discuss two other seemingly related discrepancies and then consider their possible explanation in terms of recrystallization of the core.

The modest $E$ values of $1.1-1.2$ or 2.3-2.5 (Table 2) contrast with the enhancement factor of $E=2.5$ recommended by Paterson (1994, p. 98), or of up to $E=8$ reported by.Jacka and Budd (1989) for ice recrystallized under shear in laboratory experiments, or up to $E=17$ reported by Shoji and Langway (1988) for ice from depth in the Greenland ice sheet (Dye-3 core), tested shortly after core recovery. These high $E$ values are associated with $c$-axis fabrics with a single sharp maximum, of radius $14-20^{\circ}$, centered at the pole of the known or presumed shear plane (Herron and others, 1985, figs $2 \mathrm{~b}$ and 6; Budd and Jacka, 1989, fig. 3c and d). The small enhancement shown by the marginal ice specimens probably results from the considerable breadth of the main $c$-axis maximum in Figure 4 (radius $\approx 31^{\circ}$ ) and also from the displacement of the maxima from the poles $\mathrm{S}$ and $\mathrm{C}$ in Figure 4. (This displacement is partly unavoidable, because the two maxima are not at $90^{\circ}$, and it is partly due to the statistical fluctuations noted in section 4.) The sensitivity of $E$ to degradation with increase in breadth of a single-fabric maximum has been indicated by Budd and Jacka (1989, fig. 9a). The degradation of $E$ due to displacement of a maximum from S or C has been treated by Paterson (1994, fig. 5.7) and by Shoji and Langway (1988, fig. 5).

The weak enhancement factor and the rather diffuse type of two-maximum fabric shown by the core specimens are what is expected for the early stages of fabric development under shear, with $\gamma \sim 0.1$, starting from ice with an isotropic fabric (Kamb, 1972, figs 13b and 15). The marginal ice studied here has been sheared to a far greater strain, $\gamma \sim 8-40$, according to the reasoning of Echelmeyer and others (1994, p. 532): it has spent about 100-500 years in the high $\dot{\gamma}$ zone, with $\dot{\gamma} \approx 0.14 \mathrm{a}^{-1}$. The shear of $\gamma \sim 8-40$ is far greater than the $\gamma \sim 2$ that is sufficient in the laboratory (Bouchez and Duval, 1982) and in a natural shear zone in the Barnes Ice Cap (Hudleston, 1977, p. 145) to eliminate the secondary maximum and sharpen the main maximum to a radius $\approx 20^{\circ}$, giving a large flow enhancement such as the $E=8$ indicated by Jacka and Budd (1989) and the $E=17$ found by Shoji and Langway (1988). The sharp single-maximum fabric and associated large flow enhancement expected for $\gamma \geq 2$ thus contrast strongly with what the cores show. This is a discrepancy as fundamental as, and parallel to, the discrepancy noted above between our $E$ values and those of Echelmeyer and others (1994).

At all stages of the fabric-development and flow-enhancement sequence seen experimentally from $\gamma \sim 0.1$ on, strain shadows and small-angle kink boundaries in the ice grains are abundant (Kamb, 1972, p. 222, 228, 232; Wilson, 1986; Wilson and others 1986; Duval and Castelnau, 1995). They indicate internal bending due to plastic deformation by (0001) glide within the individual crystal grains. They are also common in ice from the sharp single-maximum fabric zone at depth in the ice sheets (Rigsby, 1960, p. 605; Gow and Williamson, 1976, p.1675; Gow, 1994, p. 232). In contrast, strain shadows are very rare in our specimens and kink bands are not observed.

If the marginal ice underwent annealing recrystallization between the time it was cored and the time we studied and tested it, the discrepancies discussed above could be explained, at least in a general way; post-kinematic recrystallization would probably eliminate a sharp single-fabric maximum, reduce $E$ to a modest value and eliminate strain shadows and kinks. This would allow the unrecrystallized ice in situ to have a large $E$ value and relatively small $\tau_{\mathrm{M}}$, as predicted by the model of Echelmeyer and others (1994, figs $3 \mathrm{~b}$ and 4).

Although every precaution possible under the physical constraints of the field work was taken to avoid annealing recrystallization of the core, what is the possibility that the core recrystallized anyway? No recrystallization took place subsequent to the core's arrival at the Crary Laboratory in McMurdo Station, to judge by the following evidence: 1 . Thin sections made and examined at McMurdo Station showed the same type of two-maximum fabric and the same lack of strain shadows as do thin sections made in Pasadena from the same core. 2. At McMurdo Station and in sea shipment of the ice to Port Hueneme, as well as in storage in Pasadena, the ice was kept at or below $-20^{\circ} \mathrm{C}$, which according to Gow (1994) is cold enough to prevent recrystallization (see also section 3). It therefore appears that if recrystallization occurred it was during the core drilling or during the two days involved in temporary storage and transport of the core from the drill site to McMurdo Station. Without going into all the details, we estimate that the temperature range$5^{\circ}$ to $-10^{\circ} \mathrm{C}$ applies to the surface transport and storage, with considerably lower temperatures during the flight to McMurdo Station. In the coring operation itself, done by hot-water drilling, the core was at or near the melting point for about $0.5-1 \mathrm{~h}$.

From the above time-temperature history, we can attempt to judge the likelihood of annealing recrystallization on the basis of three sources of information:

1. Steinemann $(1958$, p. 33-40) studied post-kinematic recrystallization as a function of temperature and the compressive stress $\sigma$ to which the ice was subjected prior to unloading. Table 3 is a compilation of data on the time for $50 \%$ recrystallization, extracted from his figures 34 , 35 and 36. Values for $0^{\circ} \mathrm{C}$ are extrapolated from his data for $-1.9,-4.8$ and $-11.5^{\circ} \mathrm{C}$. We take the stress $\sigma=$ $5 \times 10^{5} \mathrm{~Pa}$ as appropriate in relation to $\tau_{\mathrm{M}} \approx 2.5 \times$ $10^{5} \mathrm{~Pa}$. For the range $-5^{\circ}$ to $-10^{\circ} \mathrm{C}$, the $50 \%$ recrystallization time is $\sim 100-500 \mathrm{~h}$, somewhat longer than the actual time of about $50 \mathrm{~h}$ that the ice was actually at this temperature. For $0^{\circ} \mathrm{C}$, the $50 \%$ recrystallization time is about $5 \mathrm{~h}$, somewhat longer than the actual $0.5-1 \mathrm{~h}$. These figures would suggest that the ice core did not have enough time (but not by a wide margin) to recrystallize during the coring operation or in transit to McMurdo Station. However, the problem is that in Steinemann's experiments, deformation and annealing recrystallization were at the same temperature, whereas in our core the ice was deformed at $-24^{\circ} \mathrm{C}$ and then annealed at $0^{\circ} \mathrm{C}$ and $-5^{\circ}$ to $-10^{\circ} \mathrm{C}$. Because of the slowness of synkinematic recrystallization at $-24^{\circ} \mathrm{C}$ (Rigsby, 1960 , p.604; Paterson, 1994, p. 86), the ice deformed at that low temperature will probably be much more prone to recrystallize at or near $0^{\circ} \mathrm{C}$. This might reduce the $50 \%$ recrystallization times to or below the actual times.

2. This problem has been addressed by Wilson (1982, fig. 5), who presented time vs grain-size diagrams for recrystallization of ice that was deformed at $-10^{\circ} \mathrm{C}$ and 
then unloaded and held at $-1^{\circ} \mathrm{C}$, resulting in what he termed thermal annealing recrystallization, which is qualitatively the type of recrystallization we are trying to assess. If we suppose that the $50 \%$ recrystallization time is the time for an increase in mean grain-size halfway from the starting level to the final plateau, then $50 \%$ recrystallization times of $1 \mathrm{~d}$ and $5 \mathrm{~d}$ are indicated for compressive strain rates $3.7 \times 10^{5} \mathrm{~s}^{-1}$ and $3.5 \times 10^{-7} \mathrm{~s}^{-1}$. (The total strains were 0.11 and 0.36 , respectively.) Later, Wilson (1986, fig. 8) presented a similar diagram (but without data points or specification of strain rate or total strain) indicating a $50 \%$ recrystallization time of $0.5 \mathrm{~d}$. This again suggests that the ice did not have quite enough time to recrystallize. Deformation to a very large total strain at the lower temperature $-24^{\circ} \mathrm{C}$ followed by thermal annealing at the higher temperature $0^{\circ} \mathrm{C}$ would presumably produce more rapid recrystallization but whether it would reduce the recrystallization time-scale from 0.5 or $1 \mathrm{~d}$ to 0.5 or $1 \mathrm{~h}$ is not possible to say.

3. Daley and Kirby (1984, fig. 2) reported that an ice specimen deformed to strain 0.046 at temperature $-115^{\circ} \mathrm{C}$ and strain rate $3.5 \times 10^{-6} \mathrm{~s}^{-1}$ partially recrystallized when a face of the specimen was melted so as to freeze it on to a glass slide. The time-scale for temperatures near $0^{\circ} \mathrm{C}$ was not specified but we estimate a few secondscertainly not minutes - for the melting/freeze-on process. The deformation conditions are extreme in relation to what we are considering here (confining pressure $1200 \times 10^{5} \mathrm{~Pa}$, yield strength $870 \times 10^{5} \mathrm{~Pa}$ ) but this observation shows that very short recrystallization times can occur for deformation at low temperature followed by annealing at or near $0^{\circ} \mathrm{C}$.

The above assessments do not provide us with a definite conclusion as to the likelihood for recrystallization of our core but they make it a possibility.

There is, however, one piece of evidence that argues against post-kinematic annealing recrystallization of our core: the form of the observed $c$-axis fabric. If the fabric resulted from annealing recrystallization at or near $0^{\circ} \mathrm{C}$ from a sharp single-maximum fabric, as contemplated above, it would be expected to have the form observed by Gow (1994) in two ice samples from the sharp single-maximum zone in the Byrd Station deep ice core; the two samples were allowed to anneal for 1 month at the melting point, resulting in a three- to five-fold enlargement of grain size. A similar experiment was carried out by Rigsby (1960, p. 604), with apparently similar results. The resulting fabrics (Gow, 1994, fig. 5), although poorly defined because of the small number of grains (11 and 26) remaining in the samples

Table 3. Estimates of $50 \%$ recrystallization time $(h)$ from Steineman (1958), as a function of temperature and of compressive stress $\sigma$ applied before unloading

\section{Fig. No. $\quad \sigma$}

$10^{5} \mathrm{~Pa}$

$0^{\circ} \mathrm{C}$

$-1.9^{\circ} \mathrm{C} \quad-4.8^{\circ} \mathrm{C}$

$-11.5 \mathrm{C}$

\begin{tabular}{rrrrrr}
\hline 36 & 20 & $0.2^{*}$ & 0.5 & 3 & 50 \\
36 & 10 & $1.5^{*}$ & 4 & 10 & 90 \\
35 & 5 & $5^{*}$ & 13 & 100 & 450 \\
34 & 5 & - & - & 30 & - \\
34 & 10 & - & - & 10 & - \\
\hline
\end{tabular}

Extrapolated from Steinemann's (1958) data. after recrystallization and grain growth, show a large dispersal of $c$-axes into either a random pattern or a very diffuse small-circle girdle of approximate radius $35-50^{\circ}$ centered on the position of the former sharp maximum. This pattern does not resemble the two-maximum fabric of Figure 4.

It would be quite surprising if post-kinematic recrystallization from an initial sharp single-maximum pattern of apparent rotational symmetry would result in a pattern that is not rotationally symmetric and that fairly well resembles the two-maximum fabric produced experimentally by shear-induced recrystallization from an initially isotropic fabric (Kamb, 1972). The resemblance is good enough that the marginal-zone fabric can be used (section 4) to identify the orientation of the shear plane and the sense of shear across it. The sense comes out consistently correct, which is a successful test of the interpretation based on the similarity to the experimental fabrics. (A more complete test is not possible, because the azimuthal orientation of the core is not known, other than from the fabric, as discussed in section 4 .

Wilson (1982, figs 7 and 8) gave $c$-axis fabrics as a function of thermal annealing time for the specimens discussed above. They start, before annealing, with a more or less well-developed fabric with two broad, sub-equal maxima, which results from pure shear deformation, as can be expected (e.g. Kamb, 1972, figs 17a and 18). For thermal annealing times of up to $8 \mathrm{~d}$, the two maxima are retained but perhaps become somewhat broader, with much statistical fluctuation. For longer times, the fabric degrades to a more or less random one. These observations suggest that, if our core underwent thermal annealing recrystallization, the in-situ fabric before recrystallization was a two-maximum fabric similar to the one we observe (Fig. 4). In this case, since the enhancement factor is determined mainly by the $c$-axis fabric (Shoji and Langway, 1988, p. 150), the enhancement factor measured from the core should be representative of the marginal ice in situ, whether or not it recrystallized, and the inferred value of the marginal shear stress (section 5) should be at least approximately correct. Why the in-situ fabric is not a sharp single maximum, according to this interpretation, is not explained.

\section{CONCLUSIONS}

Ice from the shear margin of Ice Stream B requires a shear stress of $(2.4 \pm 0.2) \times 10^{5} \mathrm{~Pa}$ to deform at the observed marginal shear strain rate $\dot{\gamma}=0.14 \mathrm{a}^{-1}$. On this basis, the average marginal shear stress, corrected for the vertical variation of ice temperature and (roughly) for crevassing, is $(2.2 \pm 0.3) \times 10^{5} \mathrm{~Pa}$. Using this value in a force-balance model of the ice stream shows that the main resistive drag that opposes the driving stress comes from the shear margins. What surface slope to use in this model is equivocal but all reasonable values give a predominating role to the margins, which provide $63-100 \%$ of the opposing drag.

The marginal shear stress $2.2 \times 10^{5} \mathrm{~Pa}$ is roughly twice as large as the value indicated by the ice-stream model of Echelmeyer and others (1994). The corresponding flow-enhancement factors differ by a factor of $5-10$. This severe discrepancy could possibly be explained by annealing recrystallization of the ice during or after core sampling. However, the form of the observed fabric is an indication that the core has not recrystallized post-kinematically or 
that, if it did recrystallize, this would not have substantially changed the fabric, as experimental data from Wilson (1982) suggest. In this case, the measured flow law, which is mainly affected by flow enhancement due to the fabric, should be applicable to the marginal ice in situ and the resulting marginal shear stress (section 5) should be correct. In case of no recrystallization, the question is why strain shadows and kinks are absent in the core and, in either case, the question is why a sharp single-maximum fabric is not present in the ice in situ, contrary to what is expected for a fabric developed at large shear strain. These and related questions raised in section 7 need to be resolved by further research before we can reach a definitive conclusion as to the marginal shear stress of Ice Stream B and as to whether we have a fundamental problem in the discrepancy between the marginal shear-stress values obtained by our method (section 5) and by the ice-stream model of Echelmeyer and others (1994).

\section{ACKNOWLEDGEMENTS}

We thank H. Engelhardt for carrying out the core drilling that furnished the core studied here, and also for providing the temperature profile in Figure $8 \mathrm{~b}$ and for help with preparation of the test apparatus and instrumentation. He was ably assisted in the difficult job of drilling in the highly crevassed Dragon by K. Echelmeyer, W. Harrison and several field assistants (C. Larsen, K. Petersen, K.-N. Swenson, S. Schmidt, E. Miya and others). We thank A. Gow, K. Echelmeyer, W. Harrison and an anonymous reviewer for helpful comments. The work was made possible by grants OPP9018703 and OPP-9319018 from the U.S. National Science Foundation.

\section{REFERENCES}

Alley, R.B. 1990. West Antarctic collapse - how likely? Episodes, 13 (4), 231-238. Alley, R. B. 1992. Flow-law hypotheses for ice-sheet modeling. f. Glaciol. $38(129), 245-256$.

Alley, R. B. 1993. In search of ice-stream sticky spots. f. Glaciol., 39(133), 447-454.

Alley, R. B., D. D. Blankenship, C. R. Bentley and S.T. Rooney. 1987. Till beneath Ice Stream B. 3. Till deformation: evidence and implications. 7. Geophys. Res., 92 (B9), 8921-8929.

Bentley, C. R. 1987. Antarctic ice streams: a review. J. Geophys. Res., 92(B9), 88438858.

Bouchez, J. L. and P. Duval. 1982. The fabric of polycrystalline ice deformed in simple shear: experiments in torsion, natural deformation and geometrical interpretation. Textures Microstruct., 5, 171-190.

Budd, W. F. and T. H. Jacka. 1989. A review of ice rheology for ice sheet modelling. Cold Reg. Sci. Technol., 16(2), 107-144.

Daley, M. A. and S. H. Kirby. 1984. Thin sectioning and surface replication of ice at low temperature. F. Glaciol., 30(105), 248-250.

Duval, P. and O. Castelnau. 1995. Dynamic recrystallization of ice in polar ice sheets. J. Phys. (Paris), IV (5), Colloq. C3, 197-205. (Supplément au 3.)

Echelmeyer, K. A., W. D. Harrison, C. Larsen and J. E. Mitchell. 1994. The role of the margins in the dynamics of an active ice stream. 7 . Glaciol., 40 (136), 527-538.

Engelhardt, H. and B. Kamb. 1994. Vertical temperature profile of Ice Stream B. Antarct. 7. U.S., 28 (5), Review 1993, $63-66$.

Engelhardt, H. and B. Kamb. 1997. Basal hydraulic system of a West Antarctic ice stream: constraints from borehole observations. 7. Glaciol., 43 (144), 207-230.

Engelhardt, H. and B. Kamb. In press. Basal sliding of Ice Stream B. J. Glaciol.
Engelhardt, H., N. Humphrey, B. Kamb and M. Fahnestock. 1990. Physical conditions at the base of a fast moving Antarctic ice stream. Science, 248(4951), 57-59.

Gow, A. J. 1994. Post-drilling recrystallization of the Byrd Station deep ice core and its relevance to current and future deep-core drilling on polar ice sheets. Ann. Glaciol., 20, 231-236.

Gow, A. J. and T. Williamson. 1976. Rheological implications of the internal structure and crystal fabrics of the West Antarctic ice sheet as revealed by deep core drilling at Byrd Station. Geol. Soc. Am. Bull., 87 (12), 1665-1677.

Harrison, W. and K. Echelmeyer. 1994. Temperature measurements in the margin of Ice Stream B, 1993-1994. Antarct. J. U.S., 29(5), Review 1994, 60.

Herron, S. L. and C. C. Langway, Jr. 1982. A comparison of ice fabrics and textures at Camp Century, Greenland and Byrd Station, Antarctica. Ann. Glaciol., 3, 118-124.

Herron, S. L., C. C. Langway, Jr and K. A. Brugger. 1985. Ultrasonic velocities and crystalline anisotropy in the ice core from Dye 3, Greenland. In Langway, C. C., Jr, H. Oeschger and W. Dansgaard, eds. Greenland ice core: geophysics, geochemistry, and the environment. Washington, DC, American Geophysical Union, 23-31. (Geophysical Monograph 33.)

Hudleston, P.J. 1977. Progressive deformation and development of fabric across zones of shear in glacial ice. In Saxena, S. and S. Bhattacharji, eds. Energetics of geological processes. Amsterdam, Springer Verlag, 121-150.

Jacka, T. H. and W. F. Budd. 1989. Isotropic and anisotropic flow relations for ice dynamics. Ann. Glaciol., 12, 81-84.

Jackson, M. 1991. Repeat aerial photogrammetry of Ice Stream B, West Antarctica. (M.Sc. thesis, Ohio State University.)

Johnson, A. F. 1977. Creep characterization of transversely-isotropic metallic material. 7. Mech. Phys. Solids, 25, 117-126.

Kamb, W. B. 1959. Ice petrofabric observations from Blue Glacier, Washington, in relation to theory and experiment. F. Geophys. Res., 64 (11), 1891-1909.

Kamb, B. 1972. Experimental recrystallization of ice under stress. In Heard, H. C., I.Y. Borg, N. L. Carter and C. B. Raleigh, eds. Flow and fracture of rocks. Washington, DC, American Geophysical Union, 211-241. (Geophysical Monograph 16.)

Kamb, W. B. 1991. Rheological nonlinearity and flow instability in the deforming bed mechanism of ice stream motion. 7. Geophys. Res., 96 (B10), $16,585-16,595$.

Kamb, B. and H. Engelhardt. 1991. Antarctic Ice Stream B: conditions controlling its motion and interactions with the climate system. International Association of Hydrological Sciences Publication 208, (Symposium at St Petersburg 1990 - Glaciers-Ocean-Atmosphere Interactions), 145-154.

Lliboutry, L. A. 1993. Ice sheet dynamics. In Stone, D. B. and S. K. Runcorn, eds. Flow and creep in the Solar system: observations, modeling and theory. Dordrecht, etc., Kluwer Academic Publishers, 399-416. (NATO ASI Series E: Applied Sciences 391.)

Meier, M. F., W. B. Kamb, C. R. Allen and R. P. Sharp. 1974. Flow of Blue Glacier, Olympic Mountains, Washington, U.S.A. J. Glaciol., 13 (68), 187-212.

Paterson, W. S. B. 1994. The physics of glaciers. Third edition. Oxford, etc., Elsevier.

Raymond, C. 1996. Shear margins in glaciers and ice sheets. 7. Glaciol., $42(140), 90-102$.

Retzlaff, R., N. Lord and C. R. Bentley. 1993. Airborne-radar studies: Ice Streams A, B and C, West Antarctica. J. Glaciol., 39(133), 495-506.

Rigsby, G. P. 1960. Crystal orientation in glacier and experimentally deformed ice. J. Glaciol., 3(27), 589-606.

Shabtaie, S. and C. R. Bentley. 1988. Ice-thickness map of the West Antarctic ice streams by radar sounding. Ann. Glaciol., 11, 126-136.

Shoji, H. and C. C. Langway, Jr. 1988. Flow-law parameters of the Dye 3, Greenland, deep ice core. Ann. Glaciol., 10, 146-150.

Steinemann, S. 1958. Experimentelle Untersuchungen zur Plastizität von Eis. Beitr. Geol. Schweiz, Ser. Geotech. - Hydrol. 10.

Whillans, I. M., M. Jackson and Y. -H. Tseng. 1993. Velocity pattern in a transect across Ice Stream B, Antarctica. 7. Glaciol., 39(133), 562-572.

Wilson, C. J. L. 1982. Texture and grain growth during the annealing of ice. Textures Microstruct., 5(1), 19-31.

Wilson, C. J. L. 1986. Deformation induced recrystallization of ice: the application of in situ experiments. In Hobbs, B. E. and H. C. Heard, eds. Mineral and rock deformation: laboratory studies-the Paterson Volume. Washington, DC, American Geophysical Union, 213-232. (Geophysical Monograph 36.).

Wilson, C. J. L., J. P. Burg and J. C. Mitchell. 1986. The origin of kinks in polycrystalline ice. Tectonophysics, $127(1-2), 27-48$. 